\title{
Contribution of Human Hepatic Cytochrome P450 Isoforms to the Metabolism of Psychotropic Drugs
}

\author{
Toshiro Niwa, ${ }^{*, a, b, 1)}$ Toshifumi Shiraga, ${ }^{b, 2)}$ Ikuko Ishit, ${ }^{b, 3)}$ Akira Kagayama, ${ }^{b, 3)}$ and Akira TAkagi ${ }^{a, 1)}$ \\ ${ }^{a}$ Post-marketing Development Research Center, Fujisawa Pharmaceutical Co., Ltd.; 3-4-7 Doshomachi, Chuo-ku, Osaka \\ 541-8514, Japan: and ${ }^{b}$ Pharmacokinetic Research Laboratories, Fujisawa Pharmaceutical Co., Ltd.; 2-1-6 Kashima, \\ Yodogawa-ku, Osaka 532-8514, Japan. Received March 25, 2005; accepted May 18, 2005
}

The metabolic activities of six psychotropic drugs, diazepam, clotiazepam, tofisopam, etizolam, tandospirone, and imipramine, were determined for 14 isoforms of recombinant human hepatic cytochrome P450s (CYPs) and human liver microsomes by measuring the disappearance rate of parent compounds. In vitro kinetic studies revealed that $V_{\max } / K_{\mathrm{m}}$ values in human liver microsomes were the highest for tofisopam, followed by tandospirone>clotiazepam>imipramine, diazepam, and etizolam. Among the recombinant CYPs, CYP3A4 exhibited the highest metabolic activities of all compounds except for clotiazepam and imipramine. The metabolism of clotiazepam was catalyzed by CYP2B6, CYP3A4, CYP2C18, and CYP2C19, and imipramine was metabolized by CYP2D6 most efficiently. In addition, the metabolic activities of diazepam, clotiazepam, and etizolam in human liver microsomes were inhibited by $2.5 \mu \mathrm{M}$ ketoconazole, a CYP3A4 inhibitor, by $97.5 \%, 65.1 \%$, and $83.5 \%$, respectively, and the imipramine metabolism was not detected after the addition of 1 or $10 \mu_{\mathrm{M}}$ quinidine, a CYP2D6 inhibitor. These results suggest that the psychotropic drugs investigated are metabolized predominantly by CYP3A4, except that CYP2D6 catalyzes the metabolism of imipramine. In addition, this approach based on the disappearance rate appears to be useful for the identification of the responsible CYP isoform(s) of older drugs, for which metabolic profiles have not been reported.

Key words diazapam; clotiazepam; tofisopam; etizolam; tandospirone; imipramine

Benzodiazepines are frequently prescribed for the treatment of anxiety symptoms in Japan and bind to receptors in various regions of the brain, such as the benzodiazepine $(\omega)$ receptor. ${ }^{4}$ Diazepam is one of the most traditional benzodiazepines and is widely used as an anxiolytic or muscle relaxant. ${ }^{4)}$ Clotiazepam and etizolam were developed in Japan and introduced to the Japanese market more than 20 years ago. These are relatively short-acting thienodiazepine derivatives, in which a benzene ring of the benzodiazepine structure is replaced with a thiophene ring. ${ }^{4-6)}$ Tofisopam, an other newer class of benzodiazepine analogues, is also widely used in Japan. ${ }^{4,7)}$ Tandospirone is not a benzodiazepine derivative, but is an antianxiety drug with serotonin $1 \mathrm{~A}$ receptor agonist activity. ${ }^{4,8)}$ Imipramine, a potent inhibitor of norepinephrine reuptake at noradrenergic nerve endings, is a tricyclic antidepressant with a tertiary-amine side chain which has been used for the treatment of major depression for many years. ${ }^{9)}$

Cytochrome P450s (CYPs) comprise a superfamily of enzymes that catalyze the oxidation of a wide variety of xenobiotic chemicals, including drugs and carcinogens. ${ }^{10-12)}$ It has been reported that diazepam is mainly metabolized to temazepam (hydroxylation), followed by $N$-demethyldiazepam ( $N$-demethylation), and that temazepam formation is catalyzed by CYP3A4 and $N$-demethylation is catalyzed by CYP2C19 and CYP3A4. ${ }^{13)}$ On the other hand, imipramine is mainly metabolized via 2-hydroxylation, followed by $\mathrm{N}$ demethylation. ${ }^{14)}$ Imipramine 2-hydroxylation is mediated exclusively by CYP2D6 and partially by CYP2C19, whereas CYP2C19 and CYP1A2 are involved in $\mathrm{N}$-demethylation. ${ }^{14}$ However, there are few reports on the metabolic pathways and/or catalyzing enzymes of clotiazepam, tofisopam, etizolam, and tandospirone, which are older psychotropic drugs, in humans.

The identification of the CYP isoform(s) has generally been performed by measuring the metabolite(s) production rate with a specific pathway of metabolism. However, because the metabolic process of new drugs in the early state of drug development and of toxic compounds is not completely elucidated, the disappearance rate of a compound from incubation medium may be useful for the identification of the responsible CYP isoform(s). ${ }^{15-17)}$ This approach appears to be applicable to older drugs for which metabolic profiles have not been reported.

In the present study, we investigated the characterization of the human enzymes responsible for the biotransformation of six psychotropic drugs, diazepam, clotiazepam, tofisopam, etizolam, tandospirone, and imipramine, by measuring the disappearance rate of parent compounds. In addition, the results obtained on the disappearance rate of diazepam and imipramine were compared with the previously reported information obtained from the formation rate of the metabolite(s).

\section{MATERIALS AND METHODS}

Materials Pooled human liver microsomes from 30 individuals (lot no. 111998A) were obtained from XenoTech (Lenexa, KS, U.S.A.). Microsomes from baculovirus-infected insect cells expressing human CYP1A1, 1A2, 1B1, 2A6, 2B6, 2C8, 2C9, 2C18, 2C19, 2D6, 2E1, 3A4, 3A5, and 4A11, which were coexpressed with NADPH-cytochrome $c$ reductase, and control microsomes from wild-type insect cells were purchased from Gentest Corp. (Woburn, MA, U.S.A.). CYP2E1 and 3A4 were also coexpressed with cytochrome $b_{5}$. Etizolam and tandospirone were synthesized in the Medicinal Chemistry Research Laboratories, Fujisawa Pharmaceutical Co., Ltd. Clotiazepam and tofisopam were purchased from Mitsubishi Pharma Corporation (Osaka, Japan) and Mochida Pharmaceutical Co., Ltd. (Tokyo, Japan), respectively. Diazepam and $17 \alpha$-methyltestosterone were obtained from Wako Pure Chemicals (Osaka, Japan), 
and ketoconazole from Ultrafine Chemicals Ltd. (Manchester, U.K.). Imipramine hydrochloride, quinidine hydrochloride, glucose-6-phosphate (G6P), and glucose-6-phosphate dehydrogenase (G6PDH) were purchased from Sigma Chemical Co. (St. Louis, MO, U.S.A.). All other reagents were of the highest purity commercially available.

Determination of Diazepam Disappearance Rate The incubation mixture consisted of $0.5 \mathrm{mg} / \mathrm{ml}$ of human liver microsomes or $50 \mathrm{pmol} / \mathrm{ml}$ of recombinant CYP, an NADPHgenerating system ( $2 \mathrm{~mm} \mathrm{NADP}{ }^{+}, 10 \mathrm{~mm}$ G6P, $5 \mathrm{~mm} \mathrm{MgCl}_{2}$, 1 unit/ml of G6PDH), 100 mm phosphate buffer ( $\mathrm{pH} 7.4$ ), and 1 or $100-800 \mu \mathrm{M}$ diazepam in a final volume of $500 \mu \mathrm{l}$. For the investigation of enzymatic kinetics (method 1), incubation was carried out at $37^{\circ} \mathrm{C}$ for $40 \mathrm{~min}$, and the reaction was terminated by the addition of $4 \mathrm{ml}$ of ethyl acetate/hexane (1:1). After $50 \mu \mathrm{l}$ of $1 \mathrm{~mm} 17 \alpha$-methyltestosterone, an internal standard, and $1 \mathrm{ml}$ of $0.1 \mathrm{M} \mathrm{NaOH}$ were added, the mixture was shaken for $10 \mathrm{~min}$ and centrifuged at $1900 \mathrm{~g}$ for $5 \mathrm{~min}$. The organic phase $(3 \mathrm{ml})$ was evaporated under nitrogen. The residue was dissolved immediately in $1 \mathrm{ml}$ of HPLC mobile phase and $10 \mu \mathrm{l}$ was injected onto an HPLC column.

For the identification of CYP isoforms involved in the metabolism of diazepam (method 2), incubation was carried out at $37^{\circ} \mathrm{C}$ for $10-40 \mathrm{~min}$, and the reaction was terminated by the addition of $5 \mathrm{ml}$ of ethyl acetate/hexane $(1: 1)$. After $50 \mu \mathrm{l}$ of $5 \mu \mathrm{M} 17 \alpha$-methyltestosterone and $1 \mathrm{ml}$ of $0.1 \mathrm{M}$ $\mathrm{NaOH}$ were added, the mixture was shaken for $10 \mathrm{~min}$ and centrifuged at $1900 \mathrm{~g}$ for $5 \mathrm{~min}$. The organic phase $(4.5 \mathrm{ml})$ was evaporated under nitrogen. The residue was dissolved immediately in $200 \mu \mathrm{l}$ of HPLC mobile phase and $50 \mu \mathrm{l}$ was injected onto an HPLC column. The HPLC system consisted of a Waters model 510 pump, Waters model 712 autosampler, Waters model 481 spectrophotometer, and an analytical column YMC J'sphere ODS L-80 $(150 \times 4.6 \mathrm{~mm}$ i.d., YMC Co., Ltd., Kyoto, Japan) equipped with a Sumipak Filter PGODS $(4 \times 4 \mathrm{~mm}$ i.d., Sumica Chemical Analysis Service, Osaka, Japan). The column temperature was set at $40^{\circ} \mathrm{C}$, and the UV detector was set at $230 \mathrm{~nm}$. The mobile phase was $0.1 \%$ triethylamine, the $\mathrm{pH}$ was adjusted to 3.5 by the addition of phosphoric acid/acetonitrile $(3: 2)$, and flow rate was maintained at $1 \mathrm{ml} / \mathrm{min}$. The retention times of diazepam and $17 \alpha$-methyltestosterone were $11 \mathrm{~min}$ and $12 \mathrm{~min}$, respectively, and calibration curves were linear for diazepam concentrations from 10 to $1000 \mu \mathrm{M}$ (method 1) and from 0.02 to $2 \mu \mathrm{M}(\operatorname{method} 2)$.

Determination of Clotiazepam Disappearance Rate The incubation mixture consisted of $0.2 \mathrm{mg} / \mathrm{ml}$ of human liver microsomes or $10-25 \mathrm{pmol} / \mathrm{ml}$ of recombinant CYP, an NADPH-generating system, $100 \mathrm{~mm}$ phosphate buffer $(\mathrm{pH}$ 7.4), and $1-100 \mu \mathrm{M}$ clotiazepam in a final volume of $500 \mu \mathrm{l}$. Incubation was carried out at $37^{\circ} \mathrm{C}$ for $5-10 \mathrm{~min}$, and the reaction was terminated by the addition of $1 \mathrm{ml}$ of $0.2 \mathrm{M}$ glycine- $\mathrm{NaOH}$ buffer (pH 10.0). After $50 \mu \mathrm{l}$ of $100 \mu \mathrm{M}$ (for the investigation of enzymatic kinetics, method 3) or $30 \mu \mathrm{M}$ (for the identification of CYP isoforms involved in the metabolism of clotiazepam, method 4) of diazepam, an internal standard, and $3.5 \mathrm{ml}$ of ethyl acetate/hexane $(1: 1)$ were added, the mixture was shaken for $10 \mathrm{~min}$ and centrifuged at $1900 \boldsymbol{g}$ for $5 \mathrm{~min}$. The organic phase $(3 \mathrm{ml})$ was evaporated under nitrogen. The residue was dissolved immediately in 500 (method 3) or $200 \mu \mathrm{l}(\operatorname{method} 4)$ of HPLC mobile phase (eluent A), and $30 \mu \mathrm{l}(\operatorname{method} 3)$ or $70 \mu \mathrm{l}(\operatorname{method} 4)$ was injected onto an HPLC column. The HPLC system consisted of a Waters 2690 Alliance Separation Module, Waters model 486 spectrophotometer, and an analytical column Inertsil ODS-3 $(150 \times 4.6 \mathrm{~mm}$ i.d., GL Sciences, Tokyo, Japan) equipped with a TSK-guardgel ODS-80Ts $(3.2 \times 15 \mathrm{~mm}$, Tosoh, Tokyo, Japan). The column temperature was set at $40^{\circ} \mathrm{C}$, and the UV detector was set at $242 \mathrm{~nm}$. The mobile phase was $20 \mathrm{~mm}$ phosphate buffer ( $\mathrm{pH} 3.5) /$ acetonitrile (50:50) as eluent A, and $85 \%$ acetonitrile as eluent B. Gradient conditions were $0-15 \mathrm{~min}, 0 \% \mathrm{~B} ; 15-15.1 \mathrm{~min}, 0$ $100 \%$ B (linear gradient); $15.1-20 \mathrm{~min}, 100 \% \mathrm{~B} ; 20$ $20.1 \mathrm{~min}, 100-0 \% \mathrm{~B}$ (linear gradient); and $20.1-25 \mathrm{~min}$ $0 \% \mathrm{~B}$. The flow rate was maintained at $1 \mathrm{ml} / \mathrm{min}$ for $15 \mathrm{~min}$ and increased to $2 \mathrm{ml} / \mathrm{min}$ at $15.1 \mathrm{~min}$. The retention times of clotiazepam and diazepam were $8 \mathrm{~min}$ and $11 \mathrm{~min}$, respectively, and calibration curves were linear for clotiazepam concentrations from 0.5 to $150 \mu \mathrm{M}$ (method 3 ) or from 0.05 to $2 \mu \mathrm{M}$ (method 4$)$.

Determination of Tofisopam Disappearance Rate The incubation mixture consisted of $0.2 \mathrm{mg} / \mathrm{ml}$ of human liver microsomes or $20 \mathrm{pmol} / \mathrm{ml}$ of recombinant CYP, an NADPHgenerating system, $100 \mathrm{~mm}$ phosphate buffer (pH 7.4), and $0.2-2 \mu \mathrm{M}$ tofisopam in a final volume of $500 \mu \mathrm{l}(\operatorname{method} 5)$. Incubation was carried out at $37^{\circ} \mathrm{C}$ for $5 \mathrm{~min}$, and the reaction was terminated by the addition of $1 \mathrm{ml}$ of $0.2 \mathrm{M}$ glycine$\mathrm{NaOH}$ buffer ( $\mathrm{pH} 10.0$ ). After $50 \mu \mathrm{l}$ of $15 \mu \mathrm{M}$ diazepam, an internal standard, and $3.5 \mathrm{ml}$ of ethyl acetate/hexane $(1: 1)$ were added, the mixture was shaken for $10 \mathrm{~min}$ and centrifuged at $1900 \boldsymbol{g}$ for $5 \mathrm{~min}$. The organic phase $(3 \mathrm{ml})$ was evaporated under nitrogen. The residue was dissolved immediately in $200 \mu \mathrm{l}$ of HPLC mobile phase (eluent A), and or $60 \mu \mathrm{l}$ was injected onto an HPLC column. The same HPLC system and columns as described in the determination of the clotiazepam disappearance rate were used except that the UV detector was set at $240 \mathrm{~nm}$. The mobile phase was $0.1 \%$ triethylamine, and the $\mathrm{pH}$ was adjusted to 5.0 by the addition of phosphoric acid as eluent $\mathrm{A}$ and acetonitrile as eluent B. Gradient conditions were $0-16.5 \mathrm{~min}, 42 \% \mathrm{~B} ; 16.5-16.6 \mathrm{~min}$, $42-85 \%$ B (linear gradient); $16.6-20 \mathrm{~min}, 85 \% \mathrm{~B} ; 20$ $20.1 \mathrm{~min}, 85-42 \% \mathrm{~B}$ (linear gradient); and $20.1-25.7 \mathrm{~min}$ $42 \%$ B. The flow rate was maintained at $1 \mathrm{ml} / \mathrm{min}$ for $16.5 \mathrm{~min}$ and increased to $2 \mathrm{ml} / \mathrm{min}$ at $16.6 \mathrm{~min}$. The retention times of tofisopam and diazepam were $8 \mathrm{~min}$ and $10 \mathrm{~min}$, respectively, and calibration curves were linear for tofisopam concentrations from 0.1 to $2 \mu \mathrm{M}(\operatorname{method} 5)$.

Determination of Etizolam Disappearance Rate The incubation mixture consisted of $0.5 \mathrm{mg} / \mathrm{ml}$ of human liver microsomes or $50 \mathrm{pmol} / \mathrm{ml}$ of recombinant CYP, an NADPHgenerating system, $100 \mathrm{~mm}$ phosphate buffer ( $\mathrm{pH} 7.4)$, and 1 or $50-500 \mu \mathrm{M}$ etizolam in a final volume of $500 \mu \mathrm{l}$. For the investigation of enzymatic kinetics (method 6), incubation was carried out at $37^{\circ} \mathrm{C}$ for $40 \mathrm{~min}$, and the reaction was terminated by the addition of $4 \mathrm{ml}$ of ethyl acetate. After $50 \mu \mathrm{l}$ of $1 \mathrm{~mm}$ diazepam, an internal standard, and $1 \mathrm{ml}$ of $0.1 \mathrm{M}$ $\mathrm{NaOH}$ were added, the mixture was shaken for $10 \mathrm{~min}$ and centrifuged at $1900 \boldsymbol{g}$ for $5 \mathrm{~min}$. The organic phase $(3 \mathrm{ml})$ was evaporated under nitrogen. The residue was dissolved immediately in $1 \mathrm{ml}$ of HPLC mobile phase and $10 \mu \mathrm{l}$ was injected onto an HPLC column. For the identification of CYP isoforms involved in the metabolism of etizolam (method 7), 
incubation was carried out at $37^{\circ} \mathrm{C}$ for $5-40 \mathrm{~min}$, and the reaction was terminated by the addition of $5 \mathrm{ml}$ of ethyl acetate. After $50 \mu \mathrm{l}$ of $5 \mu \mathrm{M}$ diazepam, an internal standard, and $1 \mathrm{ml}$ of $0.1 \mathrm{M} \mathrm{NaOH}$ were added, the mixture was shaken for $10 \mathrm{~min}$ and centrifuged at $1900 \mathrm{~g}$ for $5 \mathrm{~min}$. The organic phase $(4.5 \mathrm{ml})$ was evaporated under nitrogen. The residue was dissolved immediately in $250 \mu \mathrm{l}$ of HPLC mobile phase, and $75 \mu \mathrm{l}$ was injected onto an HPLC column. The same HPLC system, columns, and mobile phase as described in the determination of the diazepam disappearance rate were used. The retention times of etizolam and diazepam were $9 \mathrm{~min}$ and $11 \mathrm{~min}$, respectively, and calibration curves were linear for etizolam concentrations from 10 to $1000 \mu \mathrm{M}$ (method 6) and from 0.02 to $2 \mu \mathrm{M}(\operatorname{method} 7)$.

Determination of Tandospirone Disappearance Rate The incubation mixture consisted of $0.05 \mathrm{mg} / \mathrm{ml}$ of human liver microsomes or 5 (for CYP3A4) or 20 (for other CYPs) $\mathrm{pmol} / \mathrm{ml}$ of recombinant CYP, an NADPH-generating system, $100 \mathrm{~mm}$ phosphate buffer $(\mathrm{pH} 7.4)$, and $1-80 \mu \mathrm{M}$ tandospirone in a final volume of $500 \mu \mathrm{l}$. For the investigation of enzymatic kinetics (method 8), incubation was carried out at $37^{\circ} \mathrm{C}$ for $10 \mathrm{~min}$, and the reaction was terminated by the addition of $4 \mathrm{ml}$ of ethyl acetate/hexane (1:1). After $50 \mu \mathrm{l}$ of $100 \mu \mathrm{M}$ diazepam, an internal standard, and $1 \mathrm{ml}$ of $0.1 \mathrm{M} \mathrm{NaOH}$ were added, the mixture was shaken for $10 \mathrm{~min}$ and centrifuged at $1900 \boldsymbol{g}$ for $5 \mathrm{~min}$. The organic phase $(3 \mathrm{ml})$ was evaporated under nitrogen. The residue was dissolved immediately in $500 \mu \mathrm{l}$ of HPLC mobile phase and $50 \mu \mathrm{l}$ was injected onto an HPLC column. The same HPLC system consisted of a Waters LC Module and an analytical column Inertsil ODS-3 $(150 \times 4.6 \mathrm{~mm}$ i.d.) equipped with a TSKguardgel ODS-80Ts $(3.2 \times 15 \mathrm{~mm})$. The column temperature was set at $35^{\circ} \mathrm{C}$, and the UV detector was set at $238 \mathrm{~nm}$. The mobile phase was $20 \mathrm{~mm}$ phosphate buffer ( $\mathrm{pH}$ 6.8)/acetonitrile $(60: 40)$, and flow rate was $1 \mathrm{ml} / \mathrm{min}$. The retention times of tandospirone and diazepam were $9 \mathrm{~min}$ and $17 \mathrm{~min}$, respectively.

For the identification of CYP isoforms involved in the metabolism of tandospirone (method 9), the reaction was terminated by the addition of $1 \mathrm{ml}$ of acetonitrile, and the mixture was shaken for $10 \mathrm{~s}$ and centrifuged at $1900 \boldsymbol{g}$ for $5 \mathrm{~min}$. After the supernatant $(200 \mu \mathrm{l})$ was diluted with water $(200 \mu \mathrm{l}), 10 \mu \mathrm{l}$ was analyzed on liquid chromatography/tandem mass spectrometry (LC/MS/MS). The LC/MS/MS system consisted of a Waters model 626 pump, Waters model 717 autosampler, TSQ7000 (ThermoQuest, San Jose, CA, U.S.A.), and an analytical column Symmetry C18 (150× $2.1 \mathrm{~mm}$ i.d., Waters). The mobile phase was $5 \mathrm{~mm}$ ammonium acetate/acetonitrile (11:9), and flow rate was maintained at $0.2 \mathrm{ml} / \mathrm{min}$. Electronspray ionization was performed under the operating conditions of $4.5 \mathrm{kV}$ of spray voltage, sheath gas setting at $70 \mathrm{psi}, 10$ units of auxiliary gas, and a heated capillary temperature of $240^{\circ} \mathrm{C}$. Collision gas (argon) pressure was maintained at 2.0 millitorr, and the collision offset voltage was $-35 \mathrm{eV}$. Calibration curves were linear for tandospirone concentrations from 0.5 to $100 \mu \mathrm{M}$ (method 8) and from 0.04 to $2 \mu \mathrm{M}$ (method 9).

Determination of Imipramine Disappearance Rate The incubation mixture consisted of $0.5 \mathrm{mg} / \mathrm{ml}$ of human liver microsomes or 10 (for CYP2D6) or 20 (for other CYPs) $\mathrm{pmol} / \mathrm{ml}$ of recombinant CYP, an NADPH-generating system, $100 \mathrm{~mm}$ phosphate buffer (pH 7.4), and $1-500 \mu \mathrm{M}$ imipramine hydrochloride in a final volume of $500 \mu \mathrm{l}$. For the investigation of enzymatic kinetics (method 10), incubation was carried out at $37^{\circ} \mathrm{C}$ for $30 \mathrm{~min}$, and the reaction was terminated by the addition of $4 \mathrm{ml}$ of ethyl acetate. After $50 \mu \mathrm{l}$ of $100 \mu \mathrm{M}$ progesterone, an internal standard, and $1 \mathrm{ml}$ of $0.1 \mathrm{M} \mathrm{NaOH}$ were added, the mixture was shaken for $10 \mathrm{~min}$ and centrifuged at $1900 \mathrm{~g}$ for $5 \mathrm{~min}$. The organic phase $(3 \mathrm{ml})$ was evaporated under nitrogen. The residue was dissolved immediately in $1 \mathrm{ml}$ of HPLC mobile phase and $50 \mu \mathrm{l}$ was injected onto an HPLC column.

For the identification of CYP isoforms involved in the metabolism of imipramine (method 11), incubation was carried out at $37^{\circ} \mathrm{C}$ for 5 (for CYP2D6), 20 (for other CYPs), or $30 \mathrm{~min}$ (for human liver microsomes), and the reaction was terminated by the addition of $5 \mathrm{ml}$ of ethyl acetate. The organic phase $(4.5 \mathrm{ml})$ was evaporated under nitrogen. The residue was dissolved immediately in $200 \mu \mathrm{l}$ of HPLC mobile phase and $75 \mu \mathrm{l}$ was injected onto an HPLC column. The same HPLC system consisted of a Waters LC Module, and an analytical column Inertsil ODS-3 $(150 \times 4.6 \mathrm{~mm}$ i.d.) equipped with a TSK-guardgel ODS-80Ts $(3.2 \times 15 \mathrm{~mm})$. The column temperature was set at $35^{\circ} \mathrm{C}$, and the UV detector was set at $220 \mathrm{~nm}$. The mobile phase was $2 \mathrm{~mm}$ sodium lauryl sulfate/acetonitrile $(45: 55)$, and flow rate was $1 \mathrm{ml} / \mathrm{min}$. The retention times of imipramine and progesterone were $11 \mathrm{~min}$ and $15 \mathrm{~min}$, respectively, and calibration curves were linear for imipramine concentrations from 1 to $500 \mu \mathrm{M}$ (method 10) and from 0.1 to $2 \mu \mathrm{M}$ (method 11).

Effects of Chemical Inhibitors The effects of quinidine and ketoconazole, a typical inhibitor of CYP2D6 and CYP3A4, respectively, ${ }^{18-20)}$ were investigated. Ketoconazole and quinidine hydrochloride were dissolved in methanol and water, respectively, and the final concentration of methanol in the incubation mixture was adjusted to $2 \%(\mathrm{v} / \mathrm{v})$. Disappearance of substrates was determined as described above.

Data Analysis All data were analyzed using the average of duplicate or triplicate determinations. In preliminary experiments, the linearity of reaction with incubation time and protein concentration was confirmed for each assay condition. For the study of enzymatic kinetics, the initial concentrations of diazepam, clotiazepam, tofisopam, etizolam, tandospirone, and imipramine in incubation mixture were 100 $800,1-100,0.2-2,50-500,1-80$, and $2-500 \mu \mathrm{M}$, respectively, and apparent kinetic parameters were estimated by fitting to Michaelis-Menten kinetics using nonlinear regression analysis (MULTI), ${ }^{21)}$ and intrinsic metabolic clearance $\left(\mathrm{CL}_{\mathrm{int}}\right)$ was calculated as a ratio of $V_{\max }$ to $K_{\mathrm{m}}$.

\section{RESULTS}

Enzymatic Kinetics of Disappearance Rates Enzymatic kinetics of the disappearance rates of six psychotropic drugs in human liver microsomes are summarized in Table 1. $K_{\mathrm{m}}$ values were the lowest for tofisopam, followed by tandospirone, imipramine $<$ clotiazepam $<$ etizolam and diazepam, and $V_{\max }$ values were the highest for clotiazepam and diazepam followed by etizolam, tandospirone $>$ tofisopam and imipramine. Therefore $V_{\max } / K_{\mathrm{m}}$ values were the highest in tofisopam followed by tandospirone $>$ clotiazepam $>$ imipramine, diazepam, and etizolam. 
Identification of CYPs Involved in the Metabolism of Psychotropic Drugs The metabolic activities of 6 psychotropic drugs by microsomes from cells expressing human CYPs are shown in Fig. 1. The CYP involved in the metabolism of five compounds was estimated at a substrate concentration of $1 \mu \mathrm{M}$, which was the same or lower than the $K_{\mathrm{m}}$ value of each compound (Table 1). The metabolism of psy-

Table 1. Apparent Kinetic Parameters for the Metabolism of Psychotropic Drugs in Human Liver Microsomes

\begin{tabular}{lccc}
\hline Compound & $\begin{array}{c}K_{\mathrm{m}} \\
(\mu \mathrm{M})\end{array}$ & $\begin{array}{c}V_{\max } \\
(\mathrm{pmol} / \mathrm{min} / \mathrm{mg} \text { protein })\end{array}$ & $\begin{array}{c}V_{\max } / K_{\mathrm{m}} \\
(\mu \mathrm{l} / \mathrm{min} / \mathrm{mg} \text { protein })\end{array}$ \\
\hline Diazepam & $292 \pm 40$ & $6208 \pm 377$ & 21.2 \\
Clotiazepam & $33.1 \pm 0.6$ & $660 \pm 66$ & 199 \\
Tofisopam & $1.08 \pm 0.02$ & $554 \pm 4$ & 513 \\
Etizolam & $219 \pm 20$ & $3244 \pm 124$ & 14.8 \\
Tandospirone & $7.21 \pm 2.51$ & $2639 \pm 386$ & 366 \\
Imipramine & $7.64 \pm 1.23$ & $271 \pm 22$ & 35.4 \\
\hline
\end{tabular}

Kinetic parameters and standard deviations were estimated using the MULTI program.
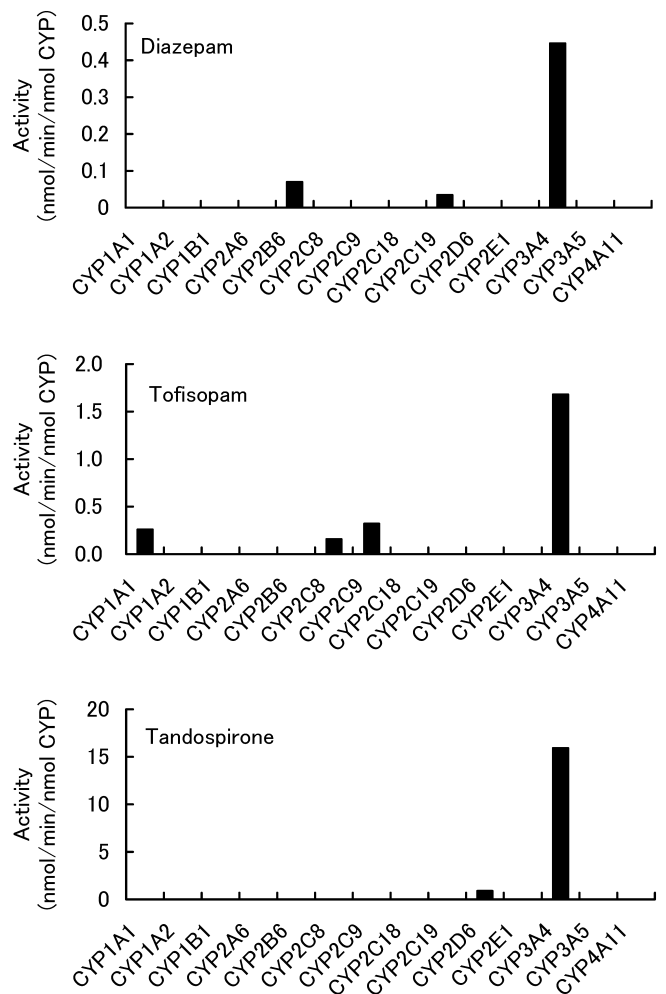

chotropic drugs, except for clotiazepam and imipramine, was catalyzed most efficiently by CYP3A4, and CYP2D6 exhibited the highest activity for imipramine metabolism. CYP2B6 catalyzed clotiazepam metabolism most efficiently, followed by CYP3A4, CYP2C18, and CYP2C19.

The inhibitory effects of ketoconazole, a typical CYP3A4 inhibitor, ${ }^{19,20)}$ on the metabolic activities of clotiazepam, which was metabolized by several CYPs including CYP3A4 (Fig. 1), diazepam, and etizolam in human liver microsomes are summarized in Table 2 . Ketoconazole $(2.5 \mu \mathrm{M})$ inhibited the metabolism of diazepam, clotiazepam, and etizolam by $97.5 \%, 65.1 \%$, and $83.5 \%$, respectively. On the other hand, the metabolic activity of imipramine was not detected in the presence of quinidine, a typical inhibitor of CYP2D6. ${ }^{18)}$

\section{DISCUSSION}

Among 14 human CYPs, CYP3A4 had the highest metabolic activities for diazepam, tofisopam, etizolam, and tandospirone, whereas clotiazepam metabolism was catalyzed
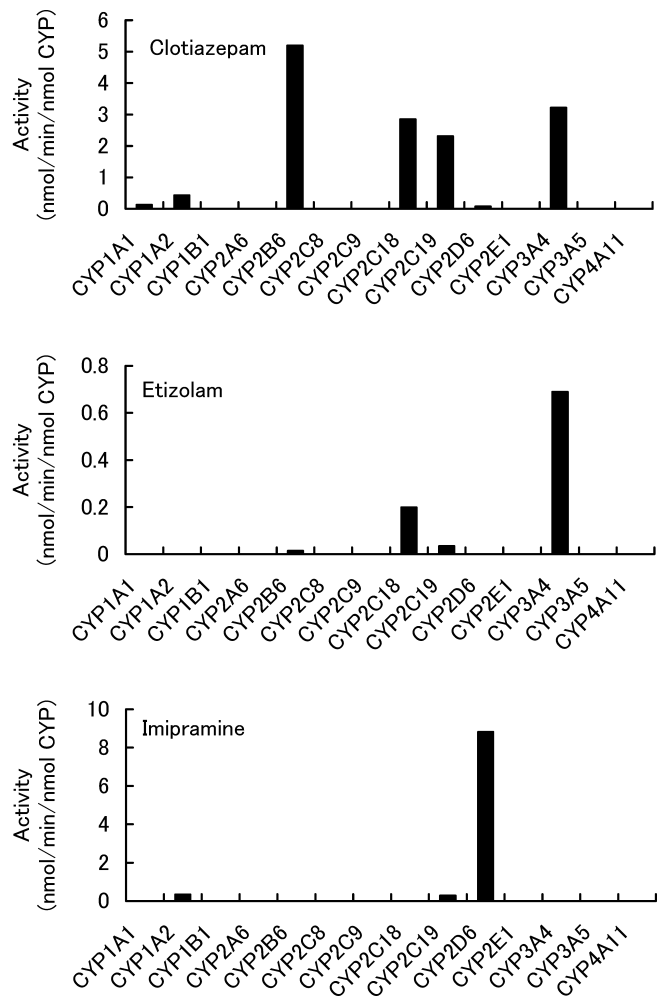

Fig. 1. Metabolic Activities of Psychotropic Drugs in Microsomes from Baculovirus-Infected Insect Cells Expressing Human CYPs

Psychotropic drugs at a concentration of $1 \mu \mathrm{M}$ were incubated with microsomes from baculovirus-infected insect cells expressing human CYPs in the presence of a NADPH-generating system as described in Materials and Methods.

Table 2. Effect of Ketoconazole and Quinidine on the Metabolism of Diazepam, Clotiazepam, Etizolam, and Imipramine

\begin{tabular}{|c|c|c|c|c|}
\hline & \multicolumn{4}{|c|}{ Activity (pmol/min/mg protein) } \\
\hline & Diazepam & Clotiazepam & Etizolam & Imipramine \\
\hline Control & $9.25(100)$ & $131.5(100)$ & $8.89(100)$ & $17.23(100)$ \\
\hline+ Ketoconazole $0.5 \mu \mathrm{M}$ & $1.64(17.7)$ & $49.1(37.4)$ & $3.05(34.3)$ & NT \\
\hline+ Ketoconazole $2.5 \mu \mathrm{M}$ & $0.23(2.5)$ & $45.9(34.9)$ & $1.47(16.5)$ & $16.76(97.2)$ \\
\hline+ Quinidine $1 \mu \mathrm{M}$ & NT & NT & NT & $<3(<17)$ \\
\hline +Quinidine $10 \mu \mathrm{M}$ & NT & NT & NT & $<3(<17)$ \\
\hline
\end{tabular}

Results represent means of duplicate or triplicate determinations, and values in parentheses are percentage of control. NT, not tested. 
Table 3. CYP Isoforms Involved in the Metabolism of Psychotropic Drugs

\begin{tabular}{|c|c|c|c|}
\hline CYP & Benzodiazepine & $\begin{array}{l}\text { Serotonin } 1 \mathrm{~A} \\
\text { receptor agonist }\end{array}$ & $\begin{array}{l}\text { Tricyclic } \\
\text { antidepressant }\end{array}$ \\
\hline CYP1A1 & (Tofisopam) & & \\
\hline CYP1A2 & & & (Imipramine) \\
\hline CYP2B6 & (Diazepam), (Clotiazepam) & & \\
\hline CYP2C8 & (Tofisopam) & & \\
\hline CYP2C9 & (Tofisopam) & & \\
\hline CYP2C18 & (Clotiazepam), (Etizolam) & & \\
\hline CYP2C19 & (Diazepam), (Clotiazepam) & & $\begin{array}{l}\text { (Imipramine), (Amitriptyline) }{ }^{24,25)} \\
{\text { (Clomipramine })^{26)}}^{(\text {I }}\end{array}$ \\
\hline CYP2D6 & & (Tandospirone) & $\begin{array}{l}\text { Imipramine, (Amitriptyline }){ }^{24)} \\
(\text { Clomipramine })^{26)}\end{array}$ \\
\hline $\begin{array}{l}\text { CYP2E1 } \\
\text { CYP3A4 }\end{array}$ & $\begin{array}{l}\text { Diazepam, Clotiazepam, Tofisopam, Etizolam, Flunitrazepam, }{ }^{21)} \\
\text { Midazolam, }^{22)} \text { Triazolam }^{23)}\end{array}$ & Tandospirone & (Amitriptyline) ${ }^{24,25)}$ (Clomipramine) ${ }^{26)}$ \\
\hline
\end{tabular}

Compounds in parentheses show the minor or partial contribution of CYP.

most efficiently by CYP2B6, followed by CYP3A4, CYP2C18, and CYP2C19 (Fig. 1). On the other hand, ketoconazole, a typical inhibitor of CYP3A4, ${ }^{19,20)}$ had strong inhibitory effects on the metabolism of clotiazepam as well as diazepam and etizolam (Table 2), suggesting that these compounds are mainly metabolized by CYP3A4 in human liver microsomes. Shimada et al. ${ }^{22)}$ reported that the relative CYP3A4/5, CYP2C8/9/18/19, CYP1A2, CYP2E1, and CYP2A6 contents in human samples were $29 \%, 18 \%, 13 \%$, $7 \%$, and $4 \%$, respectively, and that the CYP2B6 level was less than $2 \%$, suggesting that the CYP3A4/5 content is more than 10-fold the CYP2B6 content. Therefore based on the respective proportion of these CYP isoforms and their specific turnover on recombinant CYPs as well as on the results of ketoconazole inhibition, CYP3A4 appears to be mainly involved in the metabolism not only of diazepam and etizolam but also of clotiazepam. On the other hand, because $34.9 \%$ of the clotiazepam disappearance rate remained in the presence of $2.5 \mu \mathrm{M}$ of ketoconazole (Table 2), this suggests a minor contribution of other CYPs, including CYP2B6 and CYP2C19. CYPs involved in clotiazepam metabolism was estimated at a substrate concentration of $1 \mu \mathrm{M}$, which is $1 / 30$ of the $K_{\mathrm{m}}$ value $(33.1 \mu \mathrm{M}$, Table 1$)$ and may be under a nearly linear condition for the metabolism of clotiazepine in human liver. In addition, the substrate concentration is comparable to the peak plasma concentration of $178.8 \mathrm{ng} / \mathrm{ml}(0.56 \mu \mathrm{M})$ after an oral dosing with $5 \mathrm{mg}$ clotiazepam in healthy volunteers, ${ }^{23)}$ and protein binding of clotiazepam in human plasma is $99 \%{ }^{24)}$ Therefore it appears that clotiazepam metabolism is catalyzed predominantly by CYP3A4, although further detailed studies will be required to evaluate the partial contribution of other CYPs.

Andersson et $a l .{ }^{13)}$ reported that diazepam is mainly metabolized to temazepam (hydroxylation) and $N$-demethyldiazepam ( $N$-demethylation), temazepam formation activity is 5-6 times greater than $N$-demethylation activity in human liver microsomes, and temazepam formation is catalyzed by CYP3A 4 and $N$-demethylation is catalyzed by CYP2C19 and CYP3A4. In addition, the $K_{\mathrm{m}}$ values of temazepam and $\mathrm{N}$-demethyldiazepam formation in human liver microsomes are $188 \mu \mathrm{M}$ and $184 \mu \mathrm{M}$, respectively. ${ }^{13)}$ Our present results, obtained from the disappearance rate of parent compounds, showed that the $K_{\mathrm{m}}$ value of the diazepam disappearance rate was $292 \mu \mathrm{M}$ (Table 1), and that CYP3A4 was mainly involved in the metabolism of diazepam, as mentioned above. On the other hand, Koyama et al. ${ }^{14)}$ reported that imipramine is mainly metabolized via 2-hydroxylation and $\mathrm{N}$-demethylation, and that the intrinsic clearance in 2-hydroxylation is 5fold higher than that for $N$-demethylation. In addition, 2-hydroxylation is mediated exclusively by CYP2D6 and partially by CYP2C19 in liver microsomes from the extensive metabolizer of CYP2C19, whereas CYP2C19 and CYP1A2 are involved in the $N$-demethylation. ${ }^{14)}$ Furthermore, $K_{\mathrm{m}}$ values of 2-hydroxylation and $N$-demethylation activities in liver microsomes from the extensive metabolizer are $5.49 \mu \mathrm{M}$ and 14.7 $\mu \mathrm{M}$, respectively. ${ }^{14)}$ The present results, obtained from the disappearance rate of parent compounds, showed that 1) the $K_{\mathrm{m}}$ value of the imipramine disappearance rate was $7.64 \mu \mathrm{M}$ (Table 1$) ; 2$ ) the metabolism of imipramine was catalyzed most efficiently by CYP2D6, followed by CYP1A2 and CYP2C19 (Fig. 1); and 3) quinidine, a typical inhibitor of CYP2D6, strongly inhibited the metabolism of imipramine (Table 2), suggesting the predominant involvement of CYP2D6. Therefore it appears that the results obtained from the disappearance rate of both diazepam and imipramine are similar to those obtained from the formation rate of the metabolites. The disappearance rate of a compound from incubation medium may be useful for the identification of the responsible CYP isoform(s) not only of new drugs in the early state of drug development and toxic compounds ${ }^{15-17)}$ but also of older drugs for which metabolic profiles have not been reported.

There are no published data on the metabolic pathways and enzymes involved in etizolam metabolism in humans, and unpublished data from the manufacturer suggest that etizolam is metabolized mainly by hydroxylation of the methyl group (1'-hydroxylation) and of the ethyl group, and that CYP3A4 catalyzes the 1 '-hydroxylation. ${ }^{25)}$ Araki et al. ${ }^{25)}$ reported that the administration of itraconazole, an inhibitor of CYP3A4, significantly increased the plasma concentration of etizolam in healthy volunteers. Importantly, the contribution of CYP3A4 to etizolam metabolism has also been demonstrated in vivo.

CYP isoforms involved in the metabolism of psychotropic drugs are summarized in Table 3. Among benzodiazepines, not only diazepam, clotiazepam, tofisopam, and etizolam but 
also flunitrazepam, ${ }^{26)}$ midazolam, ${ }^{27)}$ and triazolam ${ }^{28)}$ appear to be mainly metabolized by CYP3A4. The serotonin 1A receptor agonist tandospirone was also metabolized by CYP3A4. In contrast, among tricyclic antidepressants, imipramine, which is metabolized via 2-hydroxylation rather than $N$-demethylation, ${ }^{14)}$ was mainly catalyzed by CYP2D6, whereas other tricyclic antidepressants, such as amitriptyline ${ }^{29,30)}$ and clomipramine, ${ }^{31)}$ are metabolized via both hydroxylation and $N$-demethylation, and are mainly catalyzed by several CYPs, such as CYP2C19, CYP2D6, and CYP3A4

In conclusion, the psychotropic drugs investigated in this study were mainly metabolized by CYP3A4, except that CYP2D6 catalyzed the metabolism of imipramine. In addition, the results obtained on the disappearance rates appear to be reflected those obtained from the formation rates of the metabolite(s).

\section{REFERENCES AND NOTES}

1) Present address: Post Marketing Product Development, Astellas Pharma Inc., 3-4-7 Doshomachi, Chuo-ku, Osaka 541-8514, Japan.

2) Present address: Drug Metabolism Research Laboratories, Astellas Pharma Inc., 1-1-8 Azusawa, Itabashi-ku, Tokyo 174-8511, Japan.

3) Present address: Analysis and Pharmacokinetics Research Laboratories, Astellas Pharma Inc., 2-1-6 Kashima, Yodogawa-ku, Osaka 532-8514, Japan.

4) Yamawaki S., Eur. Neuropsychopharmacol., 9, S413-S419 (1999).

5) Greenblatt D. J., Divoll M., Abernethy D. R., Ochs H. R., Shader R. I., Clin. Pharmacokinet., 8, 233-252 (1983).

6) Tsumagari T., Nakajima A., Fukuda T., Shuto S., Kenjo T., Morimoto Y., Takigawa Y., Arzneim.-Forsch., 28, 1158-1164 (1978).

7) Horvath K., Pharmazie, 56, S56-S61 (2001).

8) Seymour P. A., Mena E. E., McLean S., Heym J., Prog. Clin. Biol. Res., 361, 453-460 (1990).

9) Baldessarini R. J., "Goodman and Gibson's the Pharmacological Basis of Therapeutics," Chapt. 19, 10th ed., ed. by Wonsiewicz M. J., Morriss J. M., McGraw-Hill, New York, 2001, pp. 447-483.
10) Gonzalez F. J., Pharmacol. Ther, 45, 1-38 (1990).

11) Guengerich F. P., FASEB J., 6, 745-748 (1992).

12) Rendic S., Drug Metab. Rev., 34, 83-448 (2002).

13) Andersson T., Miners J. O., Veronese M. E., Birkett D. J., Br. J. Clin. Pharmacol., 38, 131-137 (1994).

14) Koyama E., Chiba K., Tani M., Ishizaki T., J. Pharmacol. Exp. Ther, 281, 1199-1210 (1997).

15) Houston J. B., Biochem. Pharmacol., 47, 1469-1479 (1994).

16) Suzuki A., Iida I., Tanaka F., Akimoto M., Fukushima K., Tani M. Ishizaki T., Chiba K., Drug Metab. Dispos., 27, 1254-1259 (1999).

17) Niwa T., Fujimoto M., Kishimoto K., Yabusaki Y., Ishibashi F., Katagiri M., Biol. Pharm. Bull., 24, $1064-1067$ (2001).

18) Otton S. V., Crewe H. K., Lennard M. S., Tucker G. T., Woods H. F., J. Pharmacol. Exp. Ther, 247, 242-247 (1988).

19) Baldwin S. J., Bloomer J. C., Smith G. J., Ayrton A. D., Clarke S. E., Chenery R. J., Xenobiotica, 25, 261-270 (1995).

20) Newton D. J., Wang R. W., Lu A. Y. H., Drug Metab. Dispos., 23, 154-158 (1995).

21) Yamaoka K., Tanigawara Y., Nakagawa T., Uno T., J. PharmacobioDyn., 4, 879-885 (1981).

22) Shimada T., Yamazaki H., Mimura M., Inui Y., Guengerich F. P., J. Pharmacol. Exp. Ther, 270, 414-423 (1994).

23) Benvenuti C., Botta V., Broggini M., Gambaro V., Lodi F., Valenti M., Eur. J. Clin. Pharmacol., 37, 617-619 (1989).

24) Arendt R., Ochs H. R., Greenblatt D. J., Arzneim.-Forsch., 32, 453455 (1982).

25) Araki K., Yasui-Furukori N., Fukasawa T., Aoshima T., Suzuki A., Inoue Y., Tateishi T., Otani K., Eur. J. Clin. Pharmacol., 60, 427-430 (2004).

26) Hesse L. M., Venkatakrishnan K., von Moltke L. L., Shader R. I., Greenblatt D. J., Drug Metab. Dispos., 29, 133-140 (2001).

27) Ito K., Iwatsubo T., Kanamitsu S., Nakajima Y., Sugiyama Y., Ann. Rev. Pharmacol. Toxicol., 38, 461-499 (1998).

28) Chauret N., Gauthier A., Martin J., Nicoll-Griffith D. A., Drug Metab. Dispos., 25, 1130-1136 (1997).

29) Venkatakrishnan K., Greenblatt D. J., von Moltke L. L., Schmider J., Harmatz J. S., Shader R. I., J. Clin. Pharmacol., 38, 112-121 (1998).

30) Venkatakrishnan K., von Moltke L. L., Greenblatt D. J., J. Pharmacol. Exp. Ther., 297, 326-337 (2001).

31) Nielsen K. K., Flinois J. P., Beaune P., Brosen K., J. Pharmacol. Exp. Ther., 277, 1659-1664 (1996). 